\title{
Ian MacKenzie, Language Contact and the Future of English
}

London: Routledge, 2018

\section{Geneviève Bordet}

\section{CpenEdition}

\section{Journals}

Electronic version

URL: http://journals.openedition.org/asp/5209

DOI: 10.4000/asp.5209

ISSN: 2108-6354

\section{Publisher}

Groupe d'étude et de recherche en anglais de spécialité

Printed version

Date of publication: 1 November 2018

Number of pages: 209-213

ISSN: 1246-8185

\section{Electronic reference}

Geneviève Bordet, « lan MacKenzie, Language Contact and the Future of English », ASp [Online], 74 I 2018, Online since 01 November 2018, connection on 02 November 2020. URL : http:// journals.openedition.org/asp/5209; DOI : https://doi.org/10.4000/asp.5209

This text was automatically generated on 2 November 2020

Tous droits réservés 


\section{Ian MacKenzie, Language Contact and the Future of English}

London: Routledge, 2018

Geneviève Bordet

\section{REFERENCES}

MacKenzie, Ian. 2018. Language Contact and the Future of English. London: Routledge. 187 pp. ISBN 978-1138-55722-2. 
1 Following his 2014 study on English as a Lingua Franca (ELF), Ian MacKenzie, former professor of translation at the University of Geneva, offers a prospective point of view on the future transformations of English in a globalized context, which he describes as characterized both by the dominance of English and constant language contacts. Taking into account the fact that English is now spoken by more non-native (L2) speakers than native speakers (L1), he first wonders to which extent the existing varieties of English as used by native speakers in various countries and continents will be impacted by this new situation. The author gives a negative answer to this question, and explains why it is in fact the opposite: developing contact zones between English and other

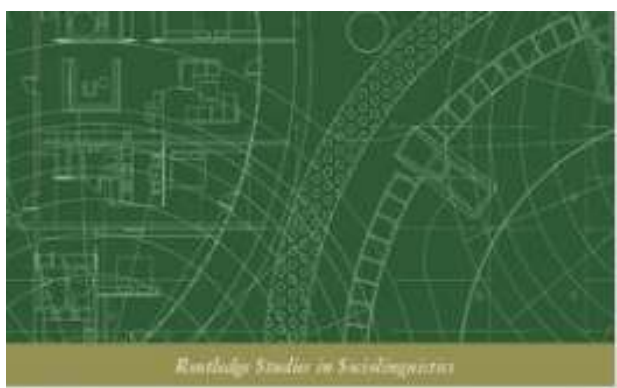

LANGUAGE CONTACT AND THE FUTURE OF ENGLISH

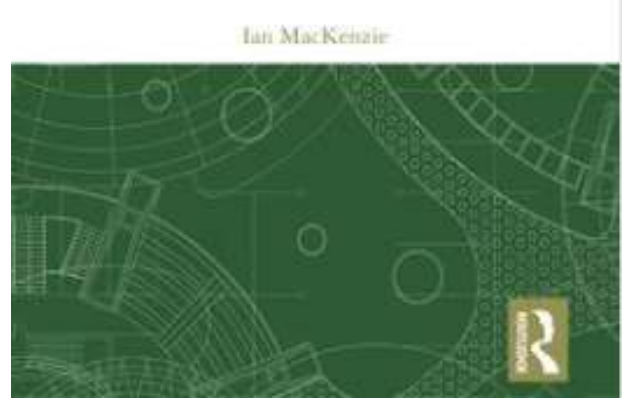
languages, through multilingualism and translation from English, are expected to increase the impact of English on other languages. He specifically sets the focus on the consequences of the dominance of English for the writers who have to publish in English as a second language, as is the case in the academic field.

2 This exploration combines a wide array of perspectives, ranging from language learning, language change and contact, bilingualism, contrastive rhetoric, and translation.

3 The volume comprises eight chapters, including the introduction and the conclusion. In the introduction, entitled "English today", the author first gives a brief synopsis of the book. He introduces the core issue of his research, i.e. the impact of the use of English by non-native speakers on the major varieties of native English in the world due to a transfer of lexicogrammatical features from other languages. Outlining the current position of English in the world, he highlights the differences between native, nativized (i.e. a variety of English spoken in multilingual countries) and ELF uses of English. He advocates a view of non-native uses of English as different and not deficient. However, he also refuses the current trend towards a rejection of the difference between nativeness and non-nativeness, arguing that the main difference is due to the amount of exposure to various registers of English and cross-linguistic interaction.

Chapter 2 deals with second language acquisition, "imperfect learning" and "multicompetences". Second language acquisition models tend to consider that the objective is to acquire native-like competence. The result is that L2 speakers are considered as deficient due to the "entrenchment" of L1 patterns and limited exposure to L2. Actually, speakers of New Englishes or English as a Lingua Franca create their own communicative strategies. Therefore while divergent uses of English do not create a specific variety of English, they give evidence of "a variable way of using it" (p. 28). Conversely, multilingualism tends to create an intercultural style based on the transfer 
of collocations from English to other native languages. The author then deals with "the spectre of native speakerism" considered as a taboo term, sometimes accused of racism and "marginalization of colonial subjects and non-citizens" (Aneja 2016: 363). Nonnativeness should in fact be considered as a "social construct", "a non-elective identity that needs to be validated by others" (p. 39) leading to the concept of "perfor-nativity".

Chapter 3 addresses the issue of language change in order to determine the influence of the influence of language contact. The author first examines the language change which can be seen as either a "random process" or, to the contrary, as the result of a purposeful action. Advocates of random change (e.g. Lass 1997) go so far as to deny any influence of language contact on language change. However, it is obvious that bilingual speakers are constantly confronted with the influence of the other language, to the extent that they tend to develop a "replica" language, in which they import L1 patterns. In a situation where all the participants in a communicative situation use English as a Lingua Franca, changes might be deliberate for various reasons, ranging from a desire to be more expressive, to avoiding misunderstandings or optimizing information structure in order to pitch to a specific audience. While speakers of ELF might introduce changes unwillingly, due to what the author calls mislearning, they may also make deliberate choices to ensure better communication with non-native speakers of English.

Chapter 4 considers the impact of ELF on English as a native language. First, a diachronic approach provides an overview of historical contact-based change in English due to its coexistence with various languages such as Norman, Cornish or Celtic. However, the current situation is very different, since native speakers of English rarely live in the same areas as ELF speakers. Besides, the development of literacy and schooling across the world prevents changes in reading and writing. While ELF speakers tend to favor the most explicit grammatical structures, this preference does not seem to impact the way native speakers use the nuances of English, even if, in a situation of communication with a majority of ELF speakers, native speakers of English might be tempted to use simpler structures so as to facilitate communication. In fact, current corpora show no clear evidence of native speakers adapting to new usages of ELF, such as the disappearance of third person singular inflection, or the use of present progressive with stative verbs.

7 In chapter 5, Ian MacKenzie explains why the dominance of English is likely to be longlived. He examines the alternatives to English used as a "hypercentral" language (Swaan 2001) to show that they are likely to be useful complements rather than replacements. The need for translation and localization does not prevent the necessity to use a common language in business negotiations. While "receptive multilingualism" (Eco 1995) is very useful for communication between speakers of contact languages, its use is limited to non-conflictual geopolitical areas and cannot meet institutional needs. Likewise, code-switching and language meshing (Canagarajah 2012) are only efficient in informal situations of communication, in which stance is not important. Finally, while Mandarin Chinese is indeed used by a vast number of speakers, the difficulty Western L2 learners of this language would be faced with prevent it from being a credible alternative to English. As a result, "it seems to be the pragmatic pursuit of social and economic advancement, via a shared language of wider communication - in short empowerment rather than subjection to a foreign power - that is driving the global use of English" (pp. 99-100). 
Chapter 6 focuses on "academic English, epistemicide and linguistic relativity". It discusses the consequences of the obligatory use of English and its argumentative style for researchers. Academic writers do not only have to find terminological equivalents, they also need to conform to cultural argumentative choices. Western argumentation tends to favor a deductive approach and a "writer-responsible" attitude where the writer has to convince and guide the reader along the argumentative flow, while Eastern culture privileges induction, based on examples, and relies on implicit shared cultural values to ensure that the reader understands the text. Therefore the academic writer is confronted with a choice between remaining faithful to a cultural way of thinking and adapting to the dominant academic culture. While the omnipresence of English allows for the development of an international science, this situation might lead to what Karen Bennett describes as "a risk of epistemicide" ${ }^{1}$ and domain loss (Bennett 2007). To avoid this risk, the author offers several suggestions such as the systematic integration of non-native speakers on journals' editorial boards, the participation of interpreters in large international conferences and the promotion of translation. However, academic translation also has to face this dilemma between "domestication" of the argumentation to adapt it to the target culture or "foreignizing" it to express a different type of reasoning which involves the risk of a rejection by the intended audience. While researchers should be familiarized with a variety of argumentative styles, the transfer of information from one language to another will always imply leaving behind connotations and structures which are specific to the source language.

9 While the previous chapters dealt with "source language agentivity" i.e. the influence of L1 speakers on L2 English, chapter 7 examines "recipient language agentivity" i.e. the extent to which English absorbs features of other languages when it is used by nonnative speakers. The development of multilingualism and the importance of translation to English impacts the other languages' features at discursive and lexicogrammatical levels. While translation has always been a source of enrichment, it can also contribute to language impoverishment when it leads to calques and massive lexical borrowing from a dominant language. For Bennett, domesticated translation into English and the foreignizing translation from English are "vehicles of colonization" (2013: 188). Another dangerous trend is a tendency to write literature in native languages in such a standard language that it is more easily translatable, which implies for instance avoiding wordplays and all kinds of cultural references. Therefore the dominance of English impacts other languages in two ways. On the one hand, translation from English tends to bring new structures into target languages; on the other hand, writers of other native languages tend to normalize their own writing so as to increase their chances of being translated into English.

10 In a last chapter, Ian MacKenzie concludes that, far from being threatened by the practice of ELF and the numerous language contact zones created by multilingualism and translation, English actually influences other languages due to a massive practice of bilingualism and the importance of translation from English to other languages. Even writers in other languages tend to normalize their style and write for translation into English. Besides, the development of translanguaging, receptive multilingualism and automatic translation certainly tend to complement ELF in specific communicative situations but they will not replace it. While L2 speakers might deliberately change some features of ELF to facilitate communication, widespread literacy and the resulting 
standardization should prevent these minor changes from influencing native English speakers. However, to avoid the risk of epistemicide and the ensuing sterilization of scientific research, academic English should be open to variations in the expression of various argumentative styles.

While it is based on rich historical data and an extensive survey of current research in the wide variety of fields the author deals with, this book also clearly reflects the author's personal opinions and predictions. It opens perspectives while creating interesting connections between fields that are usually kept separate such as ESP, language didactics, multilingualism, and ELF. Specialists of ESP will find an interesting contextualization of the evolution of ESP as part of the wide variety of Englishes spoken and written in the world. Teachers will also find food for thought as to the ethical stakes involved in their teaching methods and choices. Translators will find the point of view of a professional who takes into account recent evolutions such as the importance taken by localization and automatic translation and their impact on this field. It is therefore a stimulating read for all the professionals involved in language teaching and researching.

\section{BIBLIOGRAPHY}

ANEJA, Geeta A. 2016. "Rethinking nativeness: Toward a dynamic paradigm of (non)native speakering". Critical Inquiry in Language Studies 13/4, 351-379.

BENNETT, Karen. 2007. "Epistemicide! The tale of a predatory discourse". The Translator 13/2, 151169.

CANAGARAJAH, Suresh. 2012. Translingual Practice: Global Englishes and cosmopolitan relations. London: Routledge.

ECO, Umberto. 1995. The Search for the Perfect Language (The Making of Europe). Trans. James

Fentress. Malden: Blackwell Publishing.

LASS, Roger. 1997. Historical Linguistics and Language Change (Vol. 81). Cambridge: Cambridge University Press.

MACKENZIE, Ian. 2014. English as a Lingua Franca: Theorizing and teaching English. London: Routledge. SWAAN, Abram de. 2001. Words of the World: The global language system. Cambridge: Polity Press.

\section{NOTES}

1. "Epistemicide, as the systematic destruction of rival forms of knowledge, is at its worst nothing less than symbolic genocide. The term 'epistemicide' was coined by the Portuguese sociologist Boaventura de Sousa Santos in his General Introduction to the multi-volume project Reinventing Social Emancipation. Toward New Manifestos (2005) to describe one of the more pernicious effects of globalization upon developing countries." (Bennett 2007: 154) 


\section{AUTHORS}

\section{GENEVIÈVE BORDET}

Université Paris Diderot Sorbonne Paris Cité, gbordet@eila.univ-paris-diderot.fr 